\title{
Programmable Colloidal Approach to Hierarchical Structures of Methylammonium Lead Bromide Perovskite Nanocrystals with Bright Photoluminescent Properties
}

\author{
Meghan B. Teunis, ${ }^{\dagger}$ Merrell A. Johnson, ${ }^{\star}$ Barry B. Muhoberac, ${ }^{\dagger}$ Soenke Seifert, $^{\S}$ and Rajesh Sardar* ${ }^{\dagger} \dagger$, I[ \\ ${ }^{\dagger}$ Department of Chemistry and Chemical Biology, Indiana University-Purdue University Indianapolis, 402 N. Blackford Street, \\ Indianapolis, Indiana 46202, United States \\ ${ }^{\ddagger}$ Department of Physics, Indiana University-Purdue University Fort Wayne, 2101 E. Coliseum Blvd., Fort Wayne, Indiana 46805, \\ United States \\ ${ }^{\S}$ X-ray Science Division, Argonne National Laboratory, Argonne, Illinois 60439, United States \\ ${ }^{I I}$ Integrated Nanosystems Development Institute, Indiana University-Purdue University Indianapolis, 402 N. Blackford Street, \\ Indianapolis, Indiana 46202, United States
}

\section{Supporting Information}

\begin{abstract}
Systematic tailoring of nanocrystal architecture could provide unprecedented control over their electronic, photophysical, and charge transport properties for a variety of applications. However, at present, manipulation of the shape of perovskite nanocrystals is done mostly by trial-and-error-based experimental approaches. Here, we report systematic colloidal synthetic strategies to prepare methylammonium lead bromide quantum platelets and quantum cubes. In order to control the nucleation and growth processes of these nanocrystals, we appropriately manipulate the solvent system, surface ligand chemistry, and reaction temperature causing syntheses into anisotropic shapes. We demonstrate that both the presence of chlorinated solvent and a long chain aliphatic amine in the reaction mixture are crucial for the formation of ultrathin quantum platelets ( $\sim 2.5 \mathrm{~nm}$ in thickness), which is driven by mesoscale-assisted growth of spherical seed nanocrystals $(\sim 1.6 \mathrm{~nm}$ in diameter) through attachment of monomers onto selective crystal facets. A combined surface and structural characterization, along with small-angle X-ray scattering analysis, confirm that the long hydrocarbon of the aliphatic amine is responsible for the well ordered hierarchical stacking of the quantum platelets of $3.5 \mathrm{~nm}$ separation. In contrast, the formation of $\sim 12 \mathrm{~nm}$ edge-length quantum cubes is a kinetically driven process in which a high flux of monomers is achieved by supplying thermal energy. The photoluminescence quantum yield of our quantum platelets $(\sim 52 \%)$ is nearly 2 -fold higher than quantum cubes. Moreover, the quantum platelets display a lower nonradiative rate constant than that found with quantum cubes, which suggests less surface trap states. Together, our research has the potential both to improve the design of synthetic methods for programmable control of shape and assembly and to provide insight into optoelectronic properties of these materials for solid-state device fabrication, e.g., light-emitting diodes, solar cells, and lasing materials.
\end{abstract}

\section{INTRODUCTION}

Over the last five years, hybrid organometal halide perovskites have received substantial attention as low-cost semiconductors for fabrication of a new generation of optoelectronic devices including solar cells, ${ }^{1-13}$ light-emitting diodes (LEDs), ${ }^{14}$ and lasers. ${ }^{15,16}$ Importantly, solar cells constructed with either thin films or bulk single crystals of organometal halide perovskites have demonstrated certified power conversion efficiency as high as $22.1 \%$ (in 2016). ${ }^{17}$ In this context, efficient transport of charge carriers (electrons and holes) over long distances without hopping is fundamental to the realization of development of highly efficient solid-state, optoelectronic devices made with hybrid perovskites. Owing to the success of efficient thin film metal chalcogenide semiconductor nanostructure-based device fabrication, ${ }^{18-23}$ we expect that anisotropically shaped, quantum confined hybrid perovskite nanocrystals will provide unique photophysical, electronic, and charge transport properties in comparison to their bulk form, thus resulting in highly efficient optoelectronic device applications. To advance our knowledge of structure-property relationships in hybrid perovskite nanocrystals, it is essential to address two key questions. How can we programmably grow anisotropically shaped nanocrystals in the reaction medium? What are their shape-dependent molecular structures and corresponding

Received: December 20, 2016

Revised: April 3, 2017

Published: April 5, 2017 


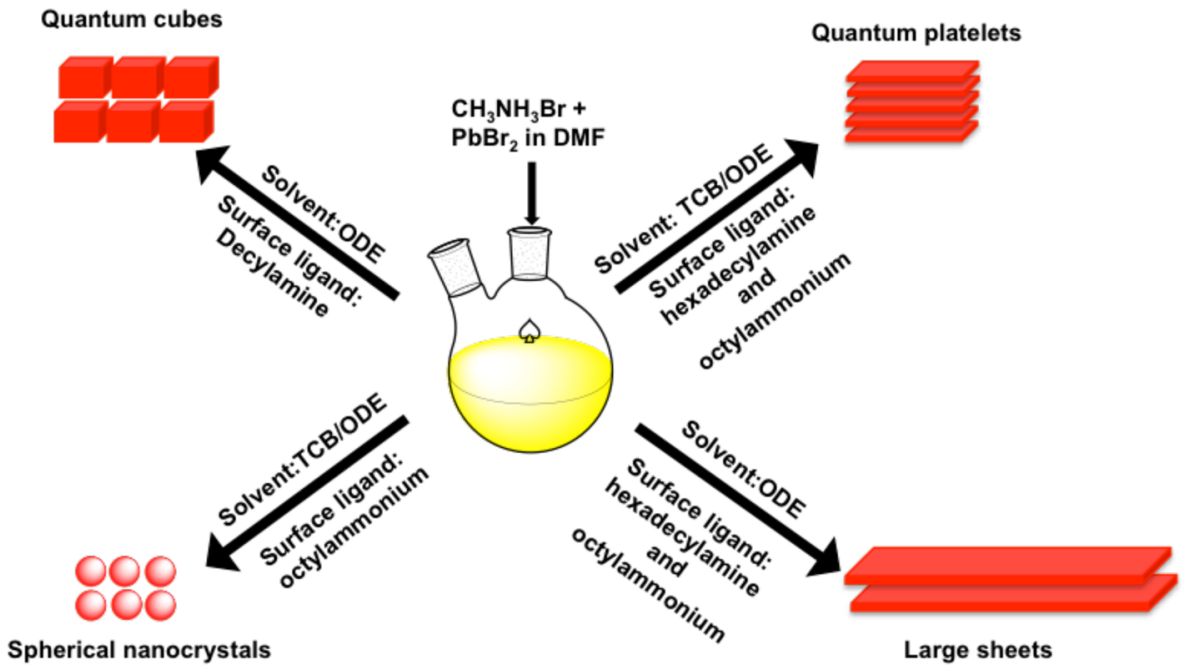

Figure 1. Solvent- and surface ligand-dependent shape evolution of $\mathrm{CH}_{3} \mathrm{NH}_{3} \mathrm{PbBr}_{3}$ perovskite nanocrystals. By controlling nucleation and growth parameters through a variety of reaction medium, surface ligands, and temperature, the shapes of the nanocrystals are systematically changed yielding a variety of structures: quantum platelets, quantum cubes, spherical nanocrystals, and large sheets. Oleic acid is present in each synthesis.

optoelectronic properties? In this Article, for the first time, we report colloidal synthesis of pseudorectangular-shaped methylammonium lead bromide $\left(\mathrm{CH}_{3} \mathrm{NH}_{3} \mathrm{PbBr}_{3}\right)$ quantum platelets, characterize their hierarchical structure, and investigate the optoelectronic properties of these ultrathin $(\sim 2.5 \mathrm{~nm})$ nanocrystals.

The first report of colloidal synthesis of spherical $\mathrm{CH}_{3} \mathrm{NH}_{3} \mathrm{PbBr}_{3}$ nanocrystals by Schmidt et al. ${ }^{24}$ was followed by preparation of hybrid organolead halide nanocrystals, ${ }^{25}$ nanowires, $^{26,27}$ and nanorods. ${ }^{28,29}$ Simultaneously, the first solution-based synthesis of all-inorganic $\mathrm{CsPbX}_{3}$ nanocrystals $(\mathrm{X}=\mathrm{Cl}, \mathrm{Br}$, and $\mathrm{I})$ by Kovalenko and co-workers ${ }^{30}$ stimulated research in the preparation of various anisotropically shaped $\mathrm{CsMX}_{3}$ nanocrystals $(\mathrm{M}=\mathrm{Pb}$ and $\mathrm{Sn}) \cdot{ }^{31-35}$ Later, Akkerman et al. synthesized pseudorectangular-shaped, two-dimension (2D) $\mathrm{CsPbX}_{3}$ nanoplatelets. ${ }^{36}$ Among all these structures, 2D semiconductor nanoplatelets (also known as quantum platelets and quantum belts) ${ }^{37-44}$ have gained substantial attention because of their high exciton binding energies and large absorption cross sections. ${ }^{45,46}$ Moreover, compared to zeroand one-dimensional nanocrystals, 2D quantum platelets possess larger lateral dimensions that increase their carrier mean-free path and reduce hopping. Furthermore, 2D quantum platelets are expected to increase the photoconversion efficiency of solar cells by minimizing carrier recombination. However, in the literature, few reports are available that demonstrate either the solution phase synthesis of large squareshaped $\mathrm{CH}_{3} \mathrm{NH}_{3} \mathrm{PbBr}_{3}$ sheets ${ }^{26,29,47,48}$ or the solid/vapor-state approach $^{49}$ and those sheets display only poor photoluminescence properties (low PL quantum yield (PLQY) and high nonradiative rate constants $\left.\left(k_{\mathrm{nr}}\right)\right)$. Therefore, in order to investigate the structure-property relationships of perovskite quantum platelets, it is important to design new synthetic methods to prepare nanocrystals of well-defined dimensionality along with enhanced photophysical properties.

Here, we report the formation of ultrathin $(<4$ unit cell thickness) pseudorectangular-shaped $\mathrm{CH}_{3} \mathrm{NH}_{3} \mathrm{PbBr}_{3}$ quantum platelets with morphology similar to that reported for CdSe and CdS quantum platelets. ${ }^{37,40,41,44}$ On the basis of our timedependent microscopy characterization, we hypothesize that our quantum platelet formation is driven by mesoscale-assisted growth of seed nanocrystals that involves cooperative van der Waals interactions between surface passivating ligands. Our small-angle X-ray scattering (SAXS) analysis suggests that the stacked quantum platelets are separated by a layer of ligand on the flat plane (001) of cubic $\mathrm{CH}_{3} \mathrm{NH}_{3} \mathrm{PbBr}_{3}$ perovskite with spacing consistent with a hexadecylamine bilayer. We have determined that the presence of a chlorinated cosolvent in the reaction mixture is a prerequisite for the formation of quantum platelets. Without establishing this experimental condition, the result is the formation of large sheets of square-shaped $\mathrm{CH}_{3} \mathrm{NH}_{3} \mathrm{PbBr}_{3}$ quantum plates of several hundred nanometers in dimension similar to those reported in the literature. ${ }^{26,47,48}$ We should mention that the concept of chlorinated solventinduced formation of anisotropically shaped nanocrystals was first reported by Weller and co-workers for $\mathrm{PbS}$ platelets. ${ }^{50}$ Importantly, by systematically tuning the thermodynamic growth regime, we are able to synthesize $\mathrm{CH}_{3} \mathrm{NH}_{3} \mathrm{PbBr}_{3}$ quantum cubes. When steady-states photophysical properties of $2.5 \pm 0.5 \mathrm{~nm}$ thick $\mathrm{CH}_{3} \mathrm{NH}_{3} \mathrm{PbBr}_{3}$ quantum platelets are compared with the $12.1 \pm 1.2 \mathrm{~nm}$ edge-length quantum cubes, we find that the $k_{\mathrm{nr}}$ is dominant in the cubes while more radiative exciton recombination takes place in the platelets. Formation of the different shapes of $\mathrm{CH}_{3} \mathrm{NH}_{3} \mathrm{PbBr}_{3}$ perovskite nanocrystals that can be achieved through appropriate manipulation of nucleation and growth conditions is outlined in Figure 1. We believe our research will provide simple and reliable but versatile synthetic methods to control the size, shape, and assembly of anisotropic perovskite nanocrystals, which still poses one of the more challenging issues in modern nanoscience-based research. The $2 \mathrm{D}$ perovskite quantum platelets with high PLQY could be envisioned as an ideal nanomaterial for molecular ink to use in semiconductor-based solid-state device fabrication.

\section{RESULTS AND DISCUSSION}

Synthesis and Structural Characterization of $\mathrm{CH}_{3} \mathrm{NH}_{3} \mathrm{PbBr}_{3}$ Quantum Platelets. We performed the synthesis of $\mathrm{CH}_{3} \mathrm{NH}_{3} \mathrm{PbBr}_{3}$ quantum platelets using a mixture of trichlorobenzene (TCB) and 1-octadecene (ODE) as cosolvents in which long-chain surface passivating ligands were dissolved (see Figure 1). Injection of soluble organic 

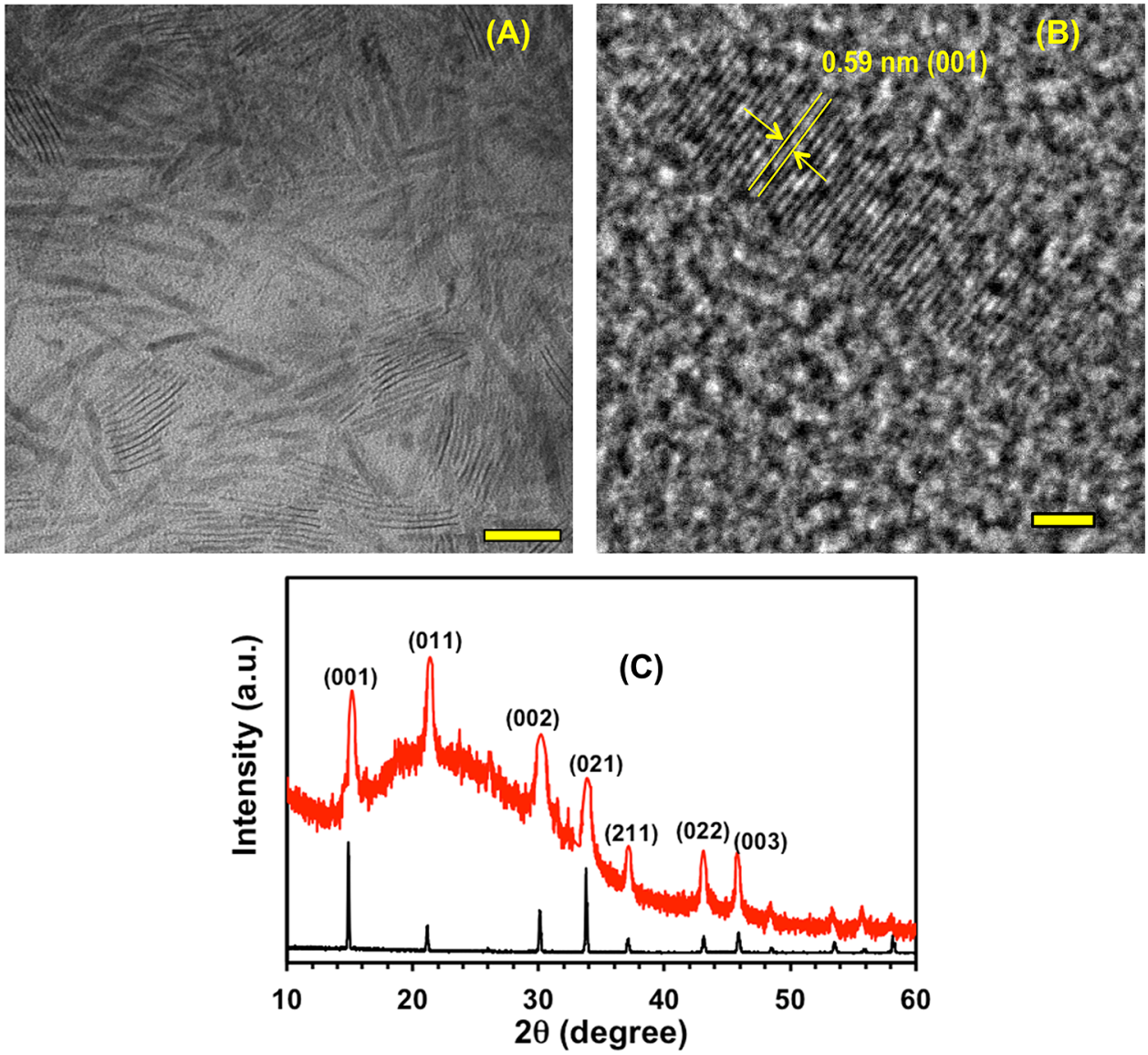

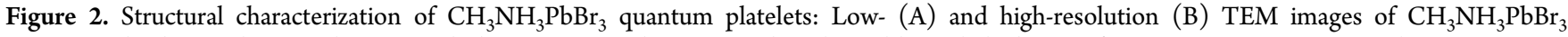
quantum platelets with 50 and $5 \mathrm{~nm}$ scale bars, respectively. Average length, width, and thickness of $55.8 \pm 4.0,8.7 \pm 1.2$, and $2.5 \pm 0.5 \mathrm{~nm}$, respectively. The lattice spacing in (B) indicates cubic crystal structure. (C) XRD pattern of the quantum platelets (red) compared with bulk singlecrystal $\mathrm{CH}_{3} \mathrm{NH}_{3} \mathrm{PbBr}_{3}$ perovskite (black), which was prepared according to a literature procedure. ${ }^{10}$ The peak position is in agreement with the cubic crystal structure of our $\mathrm{CH}_{3} \mathrm{NH}_{3} \mathrm{PbBr}_{3}$ quantum platelets. The broad peak covering $15-30^{\circ}$ is due to the glass coverslip.

cation and metal salt precursors (themselves prepared in "good" solvents) into the cosolvents resulted in formation of colloidal quantum platelets. In this unique quantum platelet synthesis, the nonpolar cosolvents act as a "poor" solvent that induces controlled crystallization of the precursors due to their lower solubility in nonpolar solvents. Briefly, oleic acid, hexadecylamine, and octylammonium bromide were dissolved in TCB-ODE cosolvents at $60{ }^{\circ} \mathrm{C}$. Separately, $\mathrm{CH}_{3} \mathrm{NH}_{3} \mathrm{Br}$ and $\mathrm{PbBr}_{2}$ precursors were prepared in $\mathrm{N}$-dimethylformamide (good solvent) and injected into the cosolvent solution, resulting in an immediate change of the solution from colorless to light yellow and indicating formation of nanocrystals. The growth was quenched with acetone, and nanocrystals were isolated by centrifugation. The detailed synthetic approach is available in the Experimental Section.

Figures $2 \mathrm{~A}$ and S1 illustrate the low- and high-resolution transmission electron microscopy (TEM) images of the $\mathrm{CH}_{3} \mathrm{NH}_{3} \mathrm{PbBr}_{3}$ quantum platelets. The platelets appeared to be pseudorectangular in shape with average length and width of $55.8 \pm 4.0$ and $8.7 \pm 1.2 \mathrm{~nm}$, respectively. In some cases, the quantum platelets were aligned perpendicular to the carbon support film of the TEM grid. We used this orientation to determine the thickness which was $2.5 \pm 0.5 \mathrm{~nm}$ corresponding to 3 monolayers of $\mathrm{CH}_{3} \mathrm{NH}_{3} \mathrm{PbBr}_{3} .{ }^{51}$ Figure $\mathrm{S} 2$ provides histograms of each dimension. From the HRTEM image (Figure 2B), an interplanar distance of $5.9 \AA$ corresponding to the (001) crystal plane was also identified. Figure $2 \mathrm{C}$ shows an $\mathrm{X}$-ray diffraction (XRD) pattern (red line) of the $\mathrm{CH}_{3} \mathrm{NH}_{3} \mathrm{PbBr}_{3}$ quantum platelets in which peaks $(2 \theta)$ at $14.9^{\circ}, 21.6^{\circ}, 30.2^{\circ}, 33.8^{\circ}, 37.0^{\circ}, 43.1^{\circ}$, and $45.6^{\circ}$ correspond to diffractions from (001), (011), (002), (021), (211), (022), and (003) planes, respectively, of cubic $\mathrm{CH}_{3} \mathrm{NH}_{3} \mathrm{PbBr}_{3}$. The pattern is in agreement with that of single crystal bulk $\mathrm{CH}_{3} \mathrm{NH}_{3} \mathrm{PbBr}_{3}$ perovskite (black line) with cubic crystal structure. ${ }^{10}$ Importantly, the XRD peaks of our $\mathrm{CH}_{3} \mathrm{NH}_{3} \mathrm{PbBr}_{3}$ quantum platelets are much broader than those of the large sheets reported in the literature ${ }^{26,29,48}$ suggesting our structure has smaller dimensions. Energy dispersive spectroscopy (EDS) characterization (Figure S3) of our quantum platelets displayed a $\mathrm{Pb} / \mathrm{Br}$ ratio of $1: 3.1$ that is in agreement with the $\mathrm{CH}_{3} \mathrm{NH}_{3} \mathrm{PbBr}_{3}$ crystal structure in which $\mathrm{Pb}$ is present in the center of an octahedron formed by six bromide ions and $\mathrm{CH}_{3} \mathrm{NH}_{3}$ is present between two octahedra. Because the octylammonium ion is much larger than $\mathrm{CH}_{3} \mathrm{NH}_{3}{ }^{+}$, it cannot incorporate into the perovskite structure. We should mention that a prolonged exposure of $\mathrm{CH}_{3} \mathrm{NH}_{3} \mathrm{PbBr}_{3}$ quantum platelets to the electron beam in the TEM analysis resulted in formation of spherical nanocrystals (Figure S4) and particles that were possibly metallic lead. This observation is in agreement with literature reports for square-shaped $\mathrm{CH}_{3} \mathrm{NH}_{3} \mathrm{PbBr}_{3}$ sheets. ${ }^{26,48}$

Steady-State Photophysical Properties of $\mathrm{CH}_{3} \mathrm{NH}_{3} \mathrm{PbBr}_{3}$ Quantum Platelets. The colloidal solution 

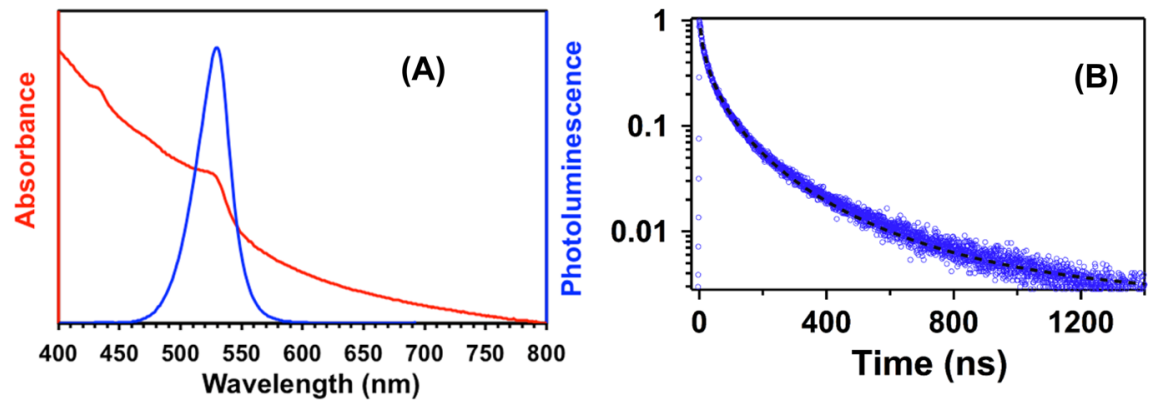

Figure 3. Solution-phase spectroscopy characterization quantum platelets: (A) UV-vis absorption (red line) and PL (blue line) spectra of $\mathrm{CH}_{3} \mathrm{NH}_{3} \mathrm{PbBr}_{3}$ in toluene. The PL spectrum was collected at $380 \mathrm{~nm}$ excitation wavelength. (B) Time-resolved emission decay (blue circles) of quantum platelets and stretched exponential fit (black dashed line) was used to determine the average lifetime.

of $\mathrm{CH}_{3} \mathrm{NH}_{3} \mathrm{PbBr}_{3}$ quantum platelets in toluene was characterized by $\mathrm{UV}$-vis, PL, and time-correlated single photon counting (TCSPC) spectroscopy. As shown in Figure 3A and listed in Table $\mathrm{S} 1$, the quantum platelets display an absorption peak at around $526 \mathrm{~nm}(2.34 \mathrm{eV})$ and PL peak at about $528 \mathrm{~nm}$ $(2.35 \mathrm{eV})$, thus having a very small Stokes shift $(10 \mathrm{meV})$. Absorption and PL peaks of quantum platelets are blue-shifted $19(90 \mathrm{meV})$ and $39(190 \mathrm{meV}) \mathrm{nm}$ compared to those of single-crystal $\mathrm{CH}_{3} \mathrm{NH}_{3} \mathrm{PbBr}_{3}$ bulk perovskite ${ }^{10}$ and blue-shifted $40 \mathrm{meV}$ in comparison to square-shaped $\mathrm{CH}_{3} \mathrm{NH}_{3} \mathrm{PbBr}_{3}$ sheets $\left(150 \mathrm{~nm}\right.$ in length and $30 \mathrm{~nm}$ in width) reported by $\mathrm{Zhu}$ et al. ${ }^{26}$ The thin dimension of our quantum platelets as compared to the excitonic Bohr radius of $\mathrm{CH}_{3} \mathrm{NH}_{3} \mathrm{PbBr}_{3}$ (estimated to be $1.4 \mathrm{~nm})^{48}$ suggests that the observed blue-shifts are attributed to quantum confinement effects. Moreover, we suggest that the optical band gap observed in our $\mathrm{CH}_{3} \mathrm{NH}_{3} \mathrm{PbBr}_{3}$ quantum platelets is due to quantum confinement in thickness rather than length or width, as suggested for CdSe quantum platelets. $^{41,44,52}$ Furthermore, the appearance of the long tail at the higher wavelength in the UV-vis spectrum (Figure $3 \mathrm{~A}$ ) indicates the presence of superstructures in solution, as discussed below.

The time-resolved PL decay curve of the quantum platelets (Figure 3B) was fitted with a stretched exponential function (see Experimental Section) to determine the average PL lifetime, which was $85 \mathrm{~ns}$. This lifetime is much shorter than for single-crystal $\mathrm{CH}_{3} \mathrm{NH}_{3} \mathrm{PbBr}_{3}$ bulk perovskite $(\sim 500 \mathrm{~ns}){ }^{10}$ Taken together, the small Stokes shifts and large lifetime are attributed to the good crystalline character of our quantum platelets in which large single-crystal facets allow PL decay through radiative recombination of photoexcited excitons. These data are also in agreement with the high PLQY of $52 \%$ for our $\mathrm{CH}_{3} \mathrm{NH}_{3} \mathrm{PbBr}_{3}$ quantum platelets. To the best of our knowledge, this is the highest PLQY reported for 2D nanocrystals of $\mathrm{CH}_{3} \mathrm{NH}_{3} \mathrm{PbBr}_{3}$ perovskites. ${ }^{26,29,48}$ Importantly, the PLQY of our three to four monolayer thick $\mathrm{CH}_{3} \mathrm{NH}_{3} \mathrm{PbBr}_{3}$ platelets is slightly higher than that reported for four monolayer thick $\mathrm{CsPbBr}_{3}$ platelets. $^{32}$ As routinely done in the literature, ${ }^{53}$ we used PLQY and PL lifetime (see Table S2) to calculate the radiative rate constant $\left(k_{\mathrm{r}}\right)$ and $k_{\mathrm{nr}}$ of our $\mathrm{CH}_{3} \mathrm{NH}_{3} \mathrm{PbBr}_{3}$ quantum platelets yielding $6.1 \times 10^{6}$ and $5.6 \times 10^{6} \mathrm{~s}^{-1}$, respectively, which are in agreement with the presence of only a few trap states in the quantum platelets and most exciton recombination taking place radiatively. We believe this is due to the combination of good quantum platelet crystalline character and their surface being nicely passivated with ligands, which mostly likely eliminated the surface defects and nonradiative trap states. It is important to mention that, although in the literature PLQY and PL lifetime are very commonly used to determine $k_{\mathrm{r}}$ and $k_{\mathrm{nr}}$, such values are a crude approximation when the measurements are conducted on an ensemble of nanocrystals. There are two contributing reasons: First, only bright nanocrystals participate in the decay dynamics of the ensemble PL measurement. Second, in contrast, "dark nanocrystals" are responsible for PLQY values but do not participate in the PL decay measurement. In our present investigation, because each quantum platelet is a potentially different emitting species, the rate constants can be considered only as phenomenological quantities. Perhaps PL study at the single nanocrystals level will provide more quantitative information regarding surface ligand controlled $k_{\mathrm{r}}$ and $k_{\mathrm{nr}}$ values, but such a study is beyond the scope of this work.

In the context of lifetime measurements, we note that the stretched exponential function is in general very commonly used to determine the average lifetime of semiconductor nanocrystals. $^{54-56}$ A two-state model with a fluorescing state and trapped state that feeds it could be used to explain the physical basis for the stretched exponential function in our system. In the model, each fluorescent center is assumed to be fed by a single, nonequivalent trap caused by variation in the local environments across the macroscopic sample, which produce a distribution of detrapping rates. Stretched exponential behavior, where the time dependence of the PL decay is described by the function $\exp \left[-(t / \tau)^{\beta}\right]$ with $0<\beta<1$ (eq 1 and 2), is associated with a steep but continuous decrease in the density of transition states. A one-parameter thermal activation model can be introduced in which the distribution of detrapping rates arises from a distribution of activation energies described by a modified Arrhenius equation. Thus, the stretched exponential model takes into account the surface traps and the recombination of the exciton from the excited state, as well as thermally activated detrapping from the traps. This model is appropriate in the case of our samples which demonstrate the presence of traps that result in moderately low PLQY 52\%.

Further investigation of the PL intensity of our quantum platelets as a function of excitation wavelength showed a constant emission wavelength maximum at $528 \mathrm{~nm}$ (see pseudocolored representation in Figure S5A). However, as shown in Figure S5B, the PL intensity decreased as the excitation wavelength decreased (excitation energy increased). We are not certain about the exact structural parameters (e.g., density of states of both ligands and quantum platelets and strength of interaction between perovskite material and organic surface ligands) that control the PL intensity under our experimental conditions. As previously suggested by Loomis 

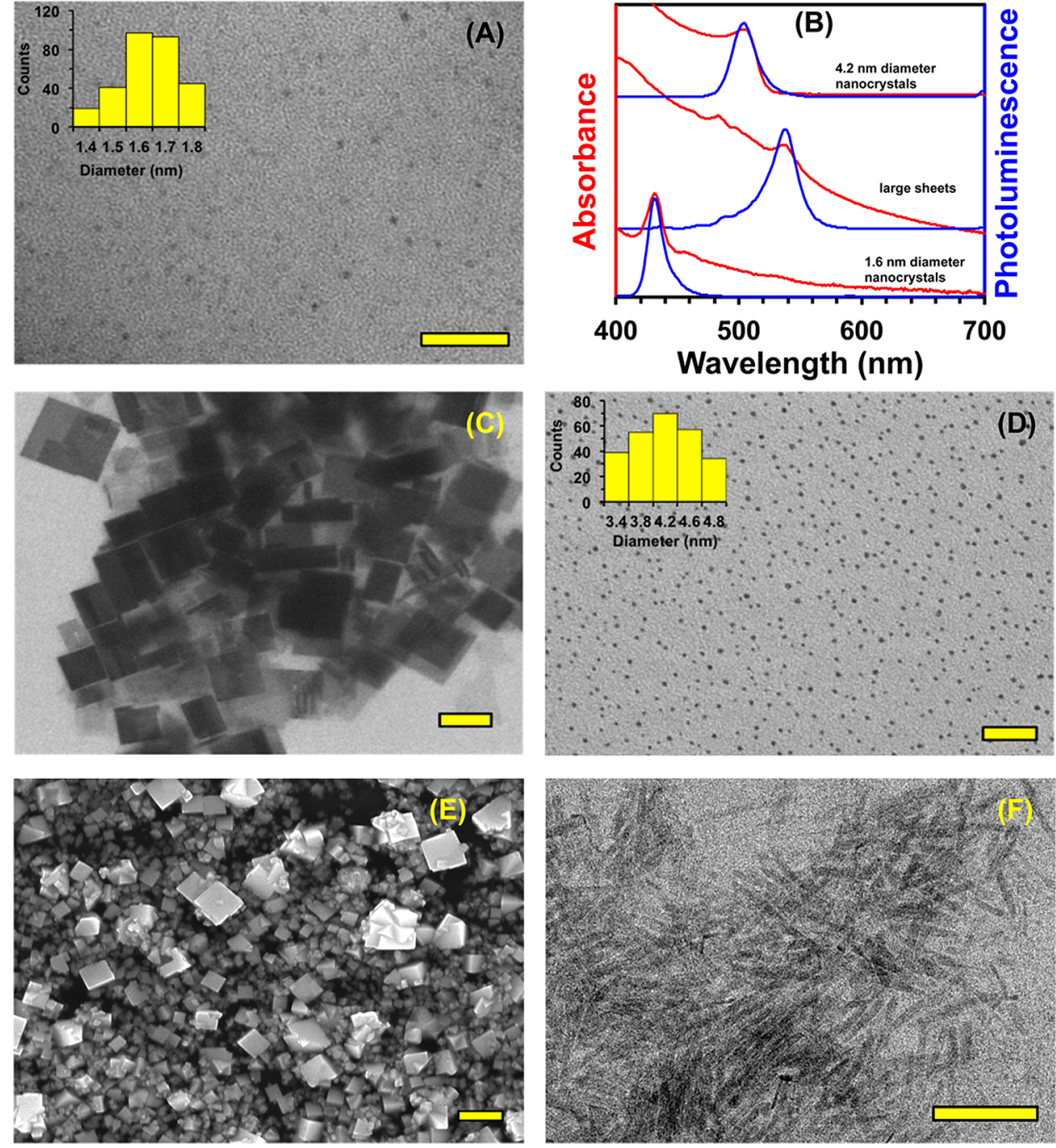

Figure 4. (A) TEM image of $1.6 \pm 0.2 \mathrm{~nm}$ diameter spherical $\mathrm{CH}_{3} \mathrm{NH}_{3} \mathrm{PbBr}_{3}$ nanocrystals isolated at $5 \mathrm{~s}$ reaction time in the quantum platelet synthesis. These nanocrystals act as precursor "seeds" for the formation of quantum platelets. Scale bar is $50 \mathrm{~nm}$. (B) UV-vis absorption (red) and PL (blue) spectra of nanocrystals shown in (A), (C), and (D). The PL spectrum was collected at $380 \mathrm{~nm}$ excitation wavelength. (C) TEM image of purified $\mathrm{CH}_{3} \mathrm{NH}_{3} \mathrm{PbBr}_{3}$ multilayer structures containing an infinite layer of unit cells (Figure 1, bottom right). Scale bar is $100 \mathrm{~nm}$. (D) TEM image of $4.2 \pm 0.4 \mathrm{~nm}$ diameter spherical $\mathrm{CH}_{3} \mathrm{NH}_{3} \mathrm{PbBr}_{3}$ nanocrystals synthesized under the same experimental conditions as quantum platelets except using octylammonium bromide (Figure 1, bottom left). Scale bar is $50 \mathrm{~nm}$. (E) SEM image of bulk $\mathrm{CH}_{3} \mathrm{NH}_{3} \mathrm{PbBr}_{3}$ perovskite synthesized in the absence of hexadecylamine. Scale bar is $1 \mu \mathrm{m}$. (F) TEM image of $\mathrm{CH}_{3} \mathrm{NH}_{3} \mathrm{PbBr}_{3}$ quantum platelets synthesized using decylamine instead of hexadecylamine. The scale bar is $100 \mathrm{~nm}$.

and co-workers (see Figure S6), ${ }^{57}$ we should also consider the electron transfer to the higher energy states of our surface passivating ligands. It is perhaps important to mention that experimental conditions such as sample concentration and excitation source intensity could contribute to a drop in PL intensity at shorter wavelengths, but these experimental errors were carefully avoided in our investigation. Thus, we believe the excitonic recombination takes place through a separate channel, possibly through the ligand monolayer instead of through direct recombination at the edge of the valence band of $\mathrm{CH}_{3} \mathrm{NH}_{3} \mathrm{PbBr}_{3}$ quantum platelets.

Comparison of the optical band gap between $\mathrm{CH}_{3} \mathrm{NH}_{3} \mathrm{PbBr}_{3}$ quantum platelets and literature reports of theoretical calculations on square-shaped sheets of similar perovskite ${ }^{48}$ reveals that our quantum platelets displayed a comparable band gap. From their calculations using the Kronig-Penny model, Sichert et al. ${ }^{48}$ suggested that, in stacked nanocrystals, as are found in our case, excitonic wave functions (electron and/or hole) could extend outside of the nanocrystal inorganic core boundary, become entangled with the wave functions of neighboring nanocrystals, and result in the formation of minibands. ${ }^{58,59}$ Under such a state of exciton wave function delocalization, the experimental optical band gap of $\mathrm{CH}_{3} \mathrm{NH}_{3} \mathrm{PbBr}_{3}$ nanocrystals will be smaller than the infinite quantum well calculation, which has also been reported for rectangular-shaped $\mathrm{CsPbBr}_{3}$ quantum platelets by Akkerman et al. $^{36}$

Formation Mechanism of $\mathrm{CH}_{3} \mathrm{NH}_{3} \mathrm{PbBr}_{3}$ Quantum Platelets and Their Hierarchical Structure. Unraveling the growth mechanisms responsible for anisotropic nanocrystals is important for preparation of various shapes and to study their structure-property relationships. According to the literature, growth mechanisms fall into two catagories: (1) growth by monomer attachment onto the growing nanocrystal as described by the classical LaMer model ${ }^{60,61}$ and (2) growth by attachment of nanocrystal commonly known as oriented 

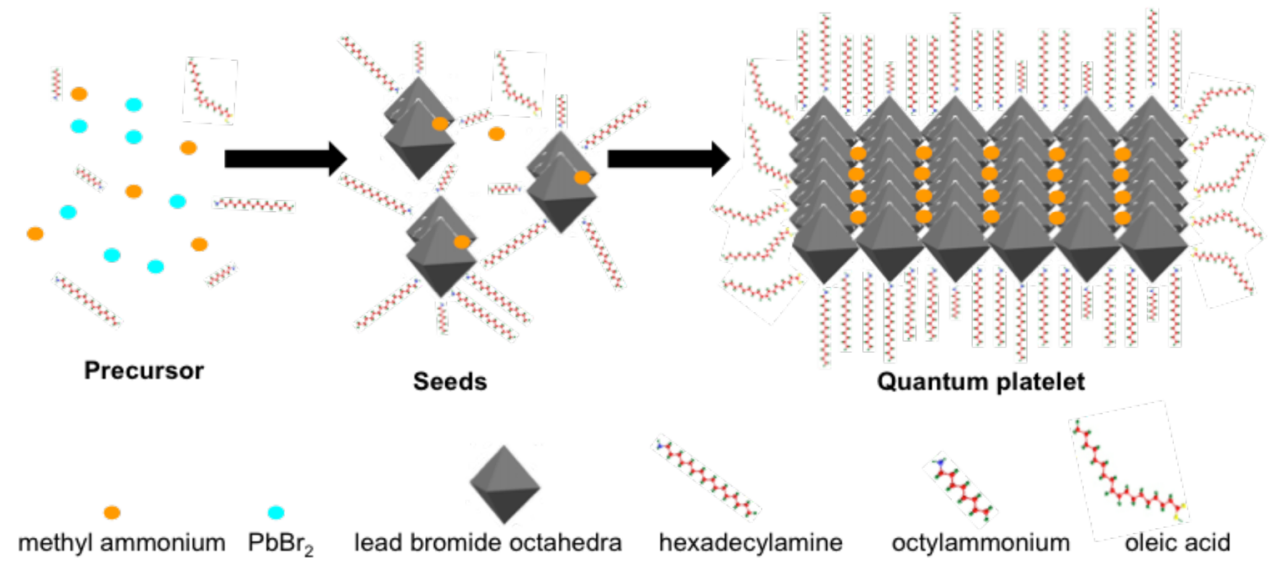

Figure 5. Schematic diagram of entropically controlled mesoscale-assisted growth of $1.6 \mathrm{~nm}$ diameter $\mathrm{CH}_{3} \mathrm{NH}_{3} \mathrm{PbBr}_{3}$ seed nanocrystals into quantum platelets. The quantum platelet growth is preferential along the length and width axes, while ligand-mediated interactions maintain the formation of $2 \mathrm{D}$ hierarchical structure. Presence of surface ligand during the entire synthesis is extremely critical in order to facilitate the cooperative interaction between the nanocrystals. We propose that octylammonium ions and hexadecylamine are attached onto the (001) plane and oleic acid is bound to (011) and (022) planes of the cubic crystal facets of $\mathrm{CH}_{3} \mathrm{NH}_{3} \mathrm{PbBr}_{3}$ perovskite.

attachment. $^{62-64}$ As shown in Figure 4A, our quantum platelet formation begins by nucleation of $1.6 \pm 0.2 \mathrm{~nm}$ diameter spherical nanocrystals, which displayed both absorption and PL emission peaks at $430 \mathrm{~nm}$ (Figure 4B) and resemble two unit cells of $\mathrm{CH}_{3} \mathrm{NH}_{3} \mathrm{PbBr}_{3}$ perovskite. ${ }^{47}$ Therefore, we suggest that $\mathrm{CH}_{3} \mathrm{NH}_{3} \mathrm{PbBr}_{3}$ quantum platelet formation is driven by mesoscale-assisted growth of seed nanocrystals ("building blocks"), which is part of mechanism (1) described above. Perhaps our growth follows 2D self-organization and in situ recrystallization of seeds as shown for ceria nanosheets ${ }^{65}$ or $2 \mathrm{D}$ template lameller structure as demonstrated with $\mathrm{CdSe}$ quantum platelets ${ }^{44,52}$ or even follows oriented assembly of seeds into ultrathin $2 \mathrm{D} \mathrm{PbS}$ sheets. ${ }^{50}$ In the case of ultrathin $\mathrm{PbS}$ sheets, ${ }^{50}$ the authors observed sheet discontinuity. However, our TEM analysis did not show such morphology, but rather, quantum platelets are quite uniform in dimension with continuous crystalline character.

In quantum platelet growth, the choice of solvents and surface ligands plays a critical role. We have found that the presence of the chlorinated solvent $\mathrm{TCB}$ in the reaction mixture is absolutely necessary in order to obtain quantum platelets. In the absence of TCB, formation of square-shaped, stacked $\mathrm{CH}_{3} \mathrm{NH}_{3} \mathrm{PbBr}_{3}$ nanosheets was observed (see Figure 4C) similar to those reported for $\mathrm{CH}_{3} \mathrm{NH}_{3} \mathrm{PbBr}_{3}{ }^{26,29,47,48}$ and $\mathrm{CsPBBr}_{3}$ sheets. ${ }^{32}$ As shown in Figure $4 \mathrm{~B}$, the photophysical properties of our sheets closely resemble those reported in the literature $^{47,48}$ and indicate formation of multilayer structures containing an infinite layer of unit cells. The stability of these large $\mathrm{CH}_{3} \mathrm{NH}_{3} \mathrm{PbBr}_{3}$ sheets under exposure to the electron beam was examined, and the sheets were found to be unstable leading to the formation of 7-10 nm diameter spherical nanocrystals, possibly of metallic $\mathrm{Pb}$, as reported earlier (Figure S7).$^{26,48,51}$ It is also important to mention that Tisdale and coworkers ${ }^{47}$ have suggested $\mathrm{CH}_{3} \mathrm{NH}_{3} \mathrm{PbBr}_{3}$ nanocrystals that are $>5.0 \mathrm{~nm}$ in diameter should not display quantum confinement effects. Therefore, the observed absorption and PL peaks at 525 and $531 \mathrm{~nm}$, respectively, reported by Schmidt et al. ${ }^{24}$ for 6.0 $\mathrm{nm}$ diameter spherical $\mathrm{CH}_{3} \mathrm{NH}_{3} \mathrm{PbBr}_{3}$ nanocrystals are likely characteristic of square-shaped $\mathrm{CH}_{3} \mathrm{NH}_{3} \mathrm{PbBr}_{3}$ large sheets that have undergone decomposition under exposure to the electron beam during TEM analysis and formed spherical nanocrytals. Moreover, TEM images of $6.0 \mathrm{~nm}$ diameter spherical
$\mathrm{CH}_{3} \mathrm{NH}_{3} \mathrm{PbBr}_{3}$ nanocrystals presented by Schmidt et al. ${ }^{24}$ are identical to those reported by $\mathrm{Zhu}$ et al. ${ }^{26}$ and Sichert et al., ${ }^{48}$ and the authors inferred formation of metallic $\mathrm{Pb}$ particles.

In an additional experiment serving as a control, formation of nearly monodispersed spherical $\mathrm{CH}_{3} \mathrm{NH}_{3} \mathrm{PbBr}_{3}$ nanocrystals of $4.2 \pm 0.4 \mathrm{~nm}$ diameter was observed when the synthesis was conducted under the same experimental conditions as quantum platelets except using octylammonium bromide (Figure 4D). A synthesis without hexadecylamine produced organically insoluble bulk $\mathrm{CH}_{3} \mathrm{NH}_{3} \mathrm{PbBr}_{3}$ material (Figure 4E), which displayed an absorption peak at $540 \mathrm{~nm}(2.3 \mathrm{eV})$ and PL peak at $545 \mathrm{~nm}(2.28 \mathrm{eV})$ (see Figure S8). Importantly, the energy gaps are much closer than those previously assigned as bulk $\mathrm{CH}_{3} \mathrm{NH}_{3} \mathrm{PbBr}_{3}$ materials in the literature. ${ }^{10}$ Thus, the optical band gaps of square-shaped $\mathrm{CH}_{3} \mathrm{NH}_{3} \mathrm{PbBr}_{3}$ sheets that are assigned as bulk band gaps in the literature ${ }^{47,48}$ may not reflect this photophysical property exactly. Perhaps some degree of quantum confinement still exists in $\mathrm{CH}_{3} \mathrm{NH}_{3} \mathrm{PbBr}_{3}$ sheets because in bulk material the band gap is expected to be $>540 \mathrm{~nm}$. Finally, we were able to synthesize $\mathrm{CH}_{3} \mathrm{NH}_{3} \mathrm{PbBr}_{3}$ quantum platelets using decylamine instead of hexadecylamine, but the ordered hierarchical stacking of the platelets was not observed (see Figure 4F). Thus, appropriate chemical structure of surface passivating ligands is required to control various interactions and to achieve higher order assemblies of the nanocrystals as discussed below.

On the basis of our systematic control experiments, we propose that $\mathrm{CH}_{3} \mathrm{NH}_{3} \mathrm{PbBr}_{3}$ quantum platelet growth is controlled by TCB and the octylammonium ion (Figure 5). At the beginning of the growth process, $1.6 \mathrm{~nm}$ diameter seeds are formed in which the planar (001) plane is passivated by octylammonium ions and hexadecylamine through chemisorption. Importantly, the presence of a long-chain amine (e.g., hexadecylamine) in the reaction mixture is critical to keeping the seeds soluble and allowing further $2 \mathrm{D}$ growth. Such growth can be categorized as mesoscale growth resulting from cooperative interactions and entropically driven processes governed by van der Waals interactions between surface ligands and electrostatic interactions between ions. ${ }^{66}$ Furthermore, a small amount of octylammonium bromide initiated the chemisorption of the cationic headgroup octylamine and inhibited the faster Oswald ripening-driven growth along the 


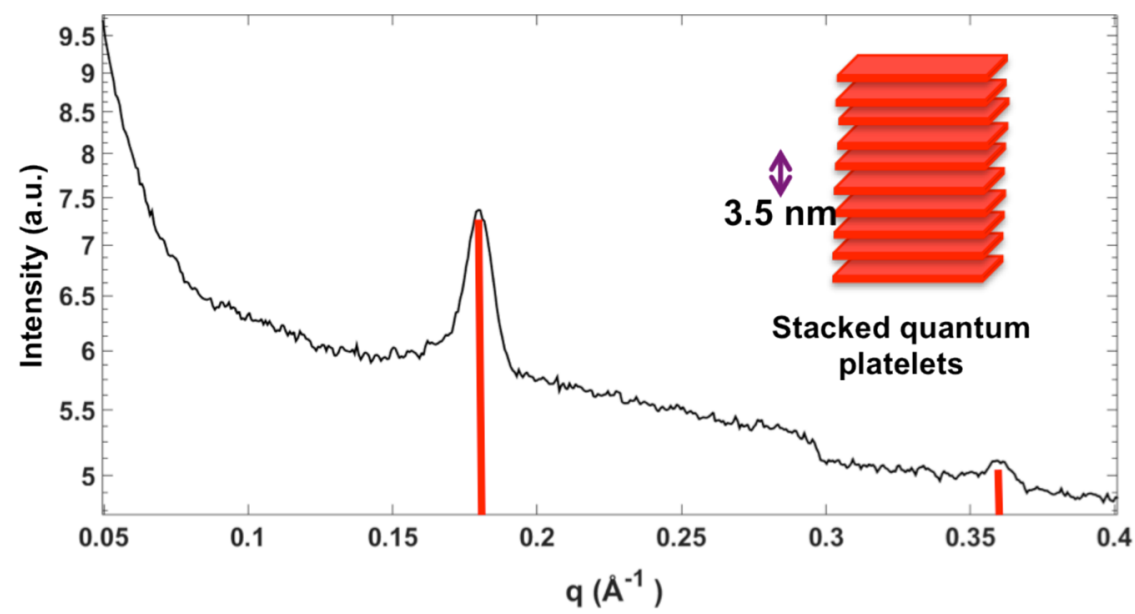

Figure 6. Small angle-X-ray scattering (SAXS) pattern of perovskite $\mathrm{CH}_{3} \mathrm{NH}_{3} \mathrm{PbBr}_{3}$ quantum platelets showing $3.5 \mathrm{~nm}$ platelet separation. The inset shows the proposed long-range order of stacked platelets. The long and short vertical red lines indicate peak positions associated with the interplatelets spacing and ordered stacked quantum platelets, respectively. For SAXS analysis, a concentrated solution of $\mathrm{CH}_{3} \mathrm{NH}_{3} \mathrm{PbBr}_{3}$ quantum platelets was spin-casted on a glass coverslip.
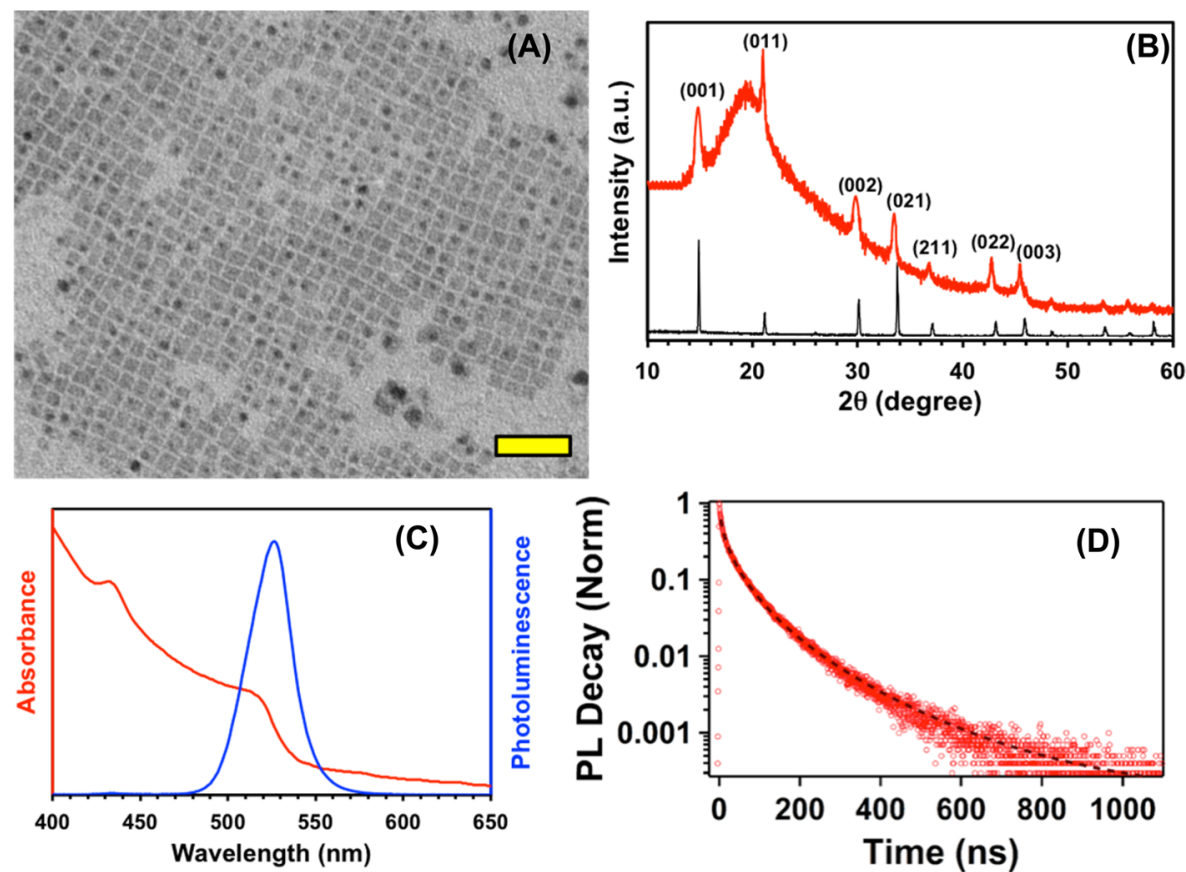

Figure 7. (A) TEM images of $\mathrm{CH}_{3} \mathrm{NH}_{3} \mathrm{PbBr}_{3}$ quantum cubes with $50 \mathrm{~nm}$ scale bar. (B) XRD pattern of quantum cubes (red) compared with the bulk, single-crystal $\mathrm{CH}_{3} \mathrm{NH}_{3} \mathrm{PbBr}_{3}$ perovskite (black), which was prepared according to the literature. ${ }^{10}$ The peak position is in agreement with cubic crystal structure of our $\mathrm{CH}_{3} \mathrm{NH}_{3} \mathrm{PbBr}_{3}$ quantum platelets. The broad peak covering $15-30^{\circ}$ is from the glass coverslip. (C) UV-vis absorption (red line) and $\mathrm{PL}$ (blue line) spectra of $\mathrm{CH}_{3} \mathrm{NH}_{3} \mathrm{PbBr}_{3}$ quantum cubes in toluene. The PL spectrum was collected at 380 nm excitation wavelength. (D) Time-resolved emission decay (red circles) of quantum cubes and stretched exponential fit (black dashed line).

(001) plane. Moreover, this plane has lower surface energy in comparison to other high index planes such as (011) and $(022){ }^{67}$ Figure S9 illustrates the different crystallographic planes of $\mathrm{CH}_{3} \mathrm{NH}_{3} \mathrm{PbBr}_{3}$ perovskite with cubic crystal structure. Taken together, we believe that the long hydrophobic chains of hexadecylamine and octylammonium ions keep the quantum platelets thinner by allowing only an additional $1-2$ unit cells to attach onto the (001) plane. ${ }^{1} \mathrm{H}$ NMR analysis showed absence of oleic acid in the seeds (Figure S10). Therefore, growth of seeds to quantum platelets occurs through continuous attachment of monomers predominantly along the (002), (003), (011), and (022) planes. Our proposed formation of quantum platelets is supported by the XRD pattern of quantum platelets in which a significant increase in intensity of these planes is observed (Figure 2C, red trace) in comparison to the standard XRD pattern of bulk $\mathrm{CH}_{3} \mathrm{NH}_{3} \mathrm{PbBr}_{3}$ perovskite (Figure $2 \mathrm{C}$, black trace). In addition, as proposed in the literature, the ability of the chlorinated solvent TCB to associate with $\mathrm{Pb}$ allows TCB to adsorb onto the reactive (002) and (003) planes and control the width. ${ }^{50}$ However, a precise understanding of the interaction between $\mathrm{Pb}$ and $\mathrm{TCB}$ is not known. Nevertheless, this control is supported by the formation of square-shaped nanosheets (Figure 4C) with comparable dimension along their length as the quantum platelets when synthesis was carried out without using TCB. Finally, the increase in length of $\mathrm{CH}_{3} \mathrm{NH}_{3} \mathrm{PbBr}_{3}$ 
quantum platelets occurs along the (011) and (022) planes. When all the monomers are consumed, oleic acid physisorbs on these planes and provides the lateral structural stabilization of $2 \mathrm{D}$ assembles. ${ }^{1} \mathrm{H}$ NMR and FTIR analyses confirm the presence of oleic acid and amines on the surface of our quantum platelets (see Figures $\mathrm{S} 10$ and $\mathrm{S} 11$ ).

As shown in Figure $2 \mathrm{~A}, \mathrm{CH}_{3} \mathrm{NH}_{3} \mathrm{PbBr}_{3}$ quantum platelets appear to self-assemble into a hierarchical structure (stacked). In order to acquire further structural information on quantum platelets, specifically interplatelets distance, we performed the small-angle X-ray scattering (SAXS) analysis with a coplanar sample position and determined an effective distance of $3.5 \pm$ $0.01 \mathrm{~nm}$ between quantum platelets (Figure 6). This value is comparable to the spacing between stacked quantum platelets of $4.0 \pm 0.2 \mathrm{~nm}$ as calculated from our TEM analysis (Figures 2A and S1). Additionally, the $34.9 \AA$ peak was accompanied by an additional higher order peak $(2 q=17.45 \AA)$, which would indicate a well ordered stacked quantum platelet. This spacing is important in the context of attachment of ligands onto the surface of our quantum platelets, specifically indicating that oleic acid is not passivating the (001) planes of $\mathrm{CH}_{3} \mathrm{NH}_{3} \mathrm{PbBr}_{3}$ perovskite. Under such circumstances, the effective distance between the stacked quantum platelets would be expected to be $<3.0 \mathrm{~nm}$, as reported by Bekenstein et al. for $\mathrm{CsPbBr}_{3}$ nanoplates. ${ }^{32}$ Therefore, TEM and SAXS analyses strengthen our proposed growth model (Figure 5) and support the idea that hexadecylamine and octylammonium attach onto the planar (001) surface of the quantum platelet. A slight reduction of interplatelet spacing in comparison to the theoretical value of $5.04 \mathrm{~nm}$, which is twice the length of the longest ligand hexadecylamine (ChemBioDraw 14.0), can be explained by partial ligand chain interdigitation. Cooperative interactions between surface passivating ligands are involved in ligand alkyl chain alignment and ligand chain interdigitation leading to mesoscale assembly. In this context, appearance of randomly oriented quantum platelets in the TEM analysis was observed when decylamine was used instead of hexadecylamine (Figure $4 \mathrm{E}$ ) in the synthesis. Thus, the presence of long-chain ligands in the reaction medium is essential for higher order assembly. Importantly, ligand-mediated interactions and formation of complex hierarchical structures through self-assembly of $2 \mathrm{D}$ nanocrystals have been documented for metal chalocogenides (e.g., $\mathrm{CdTe}, \mathrm{CdSe}$, and $\mathrm{PbS})^{41,44,50,52,68}$ and $\mathrm{CsPbX}_{3}$ nanoplates. $^{32,36}$

Synthesis and Characterization of $\mathrm{CH}_{3} \mathrm{NH}_{3} \mathrm{PbBr}_{3}$ Quantum Cubes. By systematically controlling the growth conditions, i.e., the reaction temperature and surface ligand chemistry, we obtained nearly monodispersed $\mathrm{CH}_{3} \mathrm{NH}_{3} \mathrm{PbBr}_{3}$ quantum cubes. Figures 7A and S12 illustrate the TEM images of quantum cubes having $12.1 \pm 1.2 \mathrm{~nm}$ edge-lengths. Figure $7 \mathrm{~B}$ shows the $\mathrm{XRD}$ pattern of quantum cubes that matches with the cubic crystal structure of bulk $\mathrm{CH}_{3} \mathrm{NH}_{3} \mathrm{PbBr}_{3}$ perovskite. ${ }^{10}$ The microscopic structure of our $\mathrm{CH}_{3} \mathrm{NH}_{3} \mathrm{PbBr}_{3}$ quantum cubes resembles $\mathrm{CH}_{3} \mathrm{NH}_{3} \mathrm{PbI}_{3}{ }^{29}$ or $\mathrm{CsPbX}_{3}{ }^{30,31,69}$ quantum cubes reported in the literature. As shown in Figure $7 \mathrm{C}$, the quantum cubes display an absorption peak at about $516 \mathrm{~nm}$ $(2.40 \mathrm{eV})$ and PL peak at $\sim 525 \mathrm{~nm}(2.36 \mathrm{eV})$ giving a Stokes shift of $9 \mathrm{~nm}(40 \mathrm{meV})$. The absorption and PL peaks of our quantum cubes are blue-shifted $29 \mathrm{~nm}(130 \mathrm{meV})$ when compared to that of single-crystal $\mathrm{CH}_{3} \mathrm{NH}_{3} \mathrm{PbBr}_{3}$ bulk perovskite $^{10}$ because of quantum confinement. The PLQY of our $\mathrm{CH}_{3} \mathrm{NH}_{3} \mathrm{PbBr}_{3}$ quantum cubes was determined to be $28 \%$. This value is comparable to $\mathrm{CH}_{3} \mathrm{NH}_{3} \mathrm{PbI}_{3}{ }^{29}$ quantum cubes but is nearly 3-fold lower than $\mathrm{CsPbX}_{3}$ quantum cubes. ${ }^{30,69}$ The lower PLQY of our quantum cubes could be due to relatively poorer crystalline character because of the low temperature used during synthesis $\left(110{ }^{\circ} \mathrm{C}\right)$ in comparison with $\mathrm{CsPbX}_{3}$ quantum cubes, which are commonly prepared at higher temperature $\left(>160{ }^{\circ} \mathrm{C}\right)$. Moreover, the presence of surfacerelated midgap trap states could also influence the PLQY. The average $\mathrm{PL}$ lifetime of our $\mathrm{CH}_{3} \mathrm{NH}_{3} \mathrm{PbBr}_{3}$ quantum cubes was found to be $39 \mathrm{~ns}$, as determined from the time-resolved PL decay curve (Figure 7D). Thus, the $k_{\mathrm{r}}$ and $k_{\mathrm{nr}}$ values for the quantum cubes were calculated to be $7.2 \times 10^{6}$ and $18.5 \times 10^{6}$ $\mathrm{s}^{-1}$, respectively, which suggests the presence of nonradiative trap states. Finally, examination of PL intensity as a function of excitation wavelength (Figure S13) gave an increase in intensity up to a particular wavelength and then a decrease as excitation energy continued to be increased, suggesting variable excitonic recombination channels that could also include surface passivating ligands (see Figure $\mathrm{S} 6$ ).

Growth Mechanism of $\mathrm{CH}_{3} \mathrm{NH}_{3} \mathrm{PbBr}_{3}$ Quantum Cubes. We hypothesize that the formation of $\mathrm{CH}_{3} \mathrm{NH}_{3} \mathrm{PbBr}_{3}$ quantum cubes is controlled by a kinetically driven growth process. It is known that kinetic growth requires high flux of monomers, which can be achieved by adequate supply of thermal energy $(k T) .^{70}$ In our investigation, we achieved a high flux of monomers by using a higher reaction temperature $\left(110^{\circ} \mathrm{C}\right)$ than is commonly used for $\mathrm{CH}_{3} \mathrm{NH}_{3} \mathrm{PbBr}_{3}$ nanocrystal synthesis. $^{24,28,29,47,48,50}$ Moreover, the kinetic energy barrier for transformation of monomers to nanocrystals depends on the surface energy of the crystal facets, which can be controlled by the concentration of surface passivating ligands present in the reaction mixture. Specifically, the structure and number of nanocrystal-bound surface passivating ligands control the kinetic energy barrier. In comparison to $\mathrm{CH}_{3} \mathrm{NH}_{3} \mathrm{PbBr}_{3}$ quantum platelets, quantum cubes were synthesized in the presence of a lower concentration of passivating ligands. Since oleic acid could form a self-assembled monolayer attached onto the planar (001) surface ${ }^{50}$ of a cubic crystal, growth presumably takes place along the (022) and (003) planes (see Figure S9). Moreover, in the XRD pattern of quantum cubes, a slight increase in intensity of these two planes was observed (Figure $7 \mathrm{~B}$, red trace) in comparison to the standard XRD pattern of bulk $\mathrm{CH}_{3} \mathrm{NH}_{3} \mathrm{PbBr}_{3}$ perovskite (Figure $7 \mathrm{~B}$, black trace) supporting our suggestion. Nevertheless, the roles of reaction temperature and surface ligand chemistry in the formation of anisotropically shaped perovskite nanocrystals can be more precisely determined by characterizing the seed particles, as demonstrated for metal, ${ }^{71,72}$ metal oxide, ${ }^{73}$ and metal chalocogenide semiconductor ${ }^{74}$ nanocrystals. Unfortunately, the low stability of organic-inorganic hybrid perovskite nanocrystals under electron beam exposure in TEM analysis makes such determination extremely challenging.

\section{CONCLUSION}

In summary, we present simple and versatile, programmable colloidal synthetic methods for preparation of anisotropically shaped $\mathrm{CH}_{3} \mathrm{NH}_{3} \mathrm{PbBr}_{3}$ perovskite nanocrystals in the form of quantum platelets and quantum cubes. We show that the solvent system profoundly influences the shape of the resulting nanocrystals. Although over the last two years there have been some interesting developments in the shape-controlled synthesis of colloidal organic-inorganic ${ }^{25-29,75}$ and all-inorganic $^{30-36}$ perovskite nanocrystals using trial-and-error approaches, to the best of our knowledge, here for the first time, 
pseudorectangular-shaped $\mathrm{CH}_{3} \mathrm{NH}_{3} \mathrm{PbBr}_{3}$ quantum platelets are synthesized by guiding the crystal growth process. Further development of dual solvent systems will enable the synthesis of other quantum-confined $\mathrm{CH}_{3} \mathrm{NH}_{3} \mathrm{PbBr}_{3}$ nanocrystals (e.g., quantum rods). Future studies of these anisotropically shaped perovskite nanocrystals will focus on preparation of ordered superlattices through solvent-induced self-assembly processes that will enhance the performance of nanoscale devices leading to a variety of potential future applications.

\section{EXPERIMENTAL SECTION}

Chemicals. Lead(II) bromide $\left(\mathrm{PbBr}_{2}, 99.999 \%\right)$, methylamine solution (2 $\mathrm{M}$ in THF), hydrobromic acid ( $\mathrm{HBr}, 48 \%)$, oleic acid (99\%), decylamine (99\%), hexadecylamine (90\%), 1,2,4-trichlorobenzene (TCB, 99\%), 1-octadecene (ODE, 90\%, technical grade), acetone (ACS reagent, 99.5\%), and toluene (99.5\%) were purchased from Sigma-Aldrich. N,N-Dimethylformamide was purchased from Fisher. All measurements were conducted inside the $\mathrm{N}_{2}$ filled glovebox. Commercially available ODE was kept under high vacuum overnight and transferred to the $\mathrm{N}_{2}$ filled glovebox. All sample preparation was conducted inside the glovebox. All solvents were purged with $\mathrm{N}_{2}$ for $30 \mathrm{~min}$ prior to use.

Synthesis of Methylammonium Bromide $\left(\mathrm{CH}_{3} \mathrm{NH}_{3} \mathrm{Br}\right)$ and Octylammonium Bromide $\left[\mathrm{CH}_{3}\left(\mathrm{CH}_{2}\right)_{7} \mathrm{NH}_{3} \mathrm{Br}\right]$. The bromide salts were prepared using a modified literature procedure. ${ }^{14,76}$ Briefly, $\mathrm{HBr}$ $(10.34 \mathrm{~mL}, 0.2 \mathrm{~mol})$ was added dropwise to either the methylamine solution $(7.2 \mathrm{~mL}, 0.2 \mathrm{~mol})$ or the octylamine $(32.98 \mathrm{~mL}, 0.2 \mathrm{~mol})$ with an additional $20 \mathrm{~mL}$ of ethanol and then stirred at $0{ }^{\circ} \mathrm{C}$ for $3 \mathrm{~h}$. The ethanol was removed by rotary evaporator, and the remaining solid was redissolved in a minimal amount of ethanol. Recrystallization by the addition of ether resulted in a snow-white crystalline solid, which was dried under vacuum and stored in the glovebox.

Synthesis of $\mathrm{CH}_{3} \mathrm{NH}_{3} \mathrm{PbBr}_{3}$ Quantum Platelets. In a typical $\mathrm{CH}_{3} \mathrm{NH}_{3} \mathrm{PbBr}_{3}$ quantum platelet synthesis, $1.5 \mathrm{~mL}$ of $\mathrm{ODE}, 0.5 \mathrm{~mL}$ of $\mathrm{TCB}$, and $115 \mu \mathrm{L}(0.36 \mathrm{mmol})$ of oleic acid were stirred together at room temperature for $45 \mathrm{~min}$. Separately, $3.4 \mathrm{mg}(0.016 \mathrm{mmol})$ of $\mathrm{CH}_{3}\left(\mathrm{CH}_{2}\right)_{7} \mathrm{NH}_{3} \mathrm{Br}$ and $17 \mathrm{mg}(0.07 \mathrm{mmol})$ of hexadecylamine were dissolved in $250 \mu \mathrm{L}$ of ODE and then added to oleic acid. The reaction mixture was stirred for $30 \mathrm{~min}$ at $60^{\circ} \mathrm{C}$. Then, $3.5 \mathrm{mg}(0.0315 \mathrm{mmol})$ of $\mathrm{CH}_{3} \mathrm{NH}_{3} \mathrm{Br}$ and $18.7 \mathrm{mg}(0.05 \mathrm{mmol})$ of $\mathrm{PbBr}_{2}$ were dissolved in 100 and $200 \mu \mathrm{L}$ DMF, respectively. The $\mathrm{CH}_{3} \mathrm{NH}_{3} \mathrm{Br}$ solution and $\mathrm{PbBr}_{2}$ solution were injected simultaneously into the above-mentioned reaction mixture. The solution color turned light yellow almost instantaneously. Then, $15 \mathrm{~s}$ after the addition of $\mathrm{PbBr}_{2}$ solution, a 200 $\mu \mathrm{L}$ aliquot was removed and injected into $2 \mathrm{~mL}$ of acetone to quench the growth. The solution was centrifuged at $5000 \mathrm{rpm}$ for $2 \mathrm{~min}$, and the resulting solid was then dissolved in toluene and centrifuged again at $5000 \mathrm{rpm}$ for $2 \mathrm{~min}$. The clear yellow supernatant was collected. The solution was dried under high vacuum and stored in a $3 \mathrm{~mL}$ vial capped under nitrogen.

Synthesis of $\mathrm{CH}_{3} \mathrm{NH}_{3} \mathrm{PbBr}_{3}$ Quantum Cubes. $\mathrm{CH}_{3} \mathrm{NH}_{3} \mathrm{PbBr}_{3}$ quantum cubes were synthesized as follows: In a round-bottom flask, $2.0 \mathrm{~mL}$ of ODE and $60 \mu \mathrm{L}(0.19 \mathrm{mmol})$ of oleic acid were mixed and stirred at $110{ }^{\circ} \mathrm{C}$ for $45 \mathrm{~min}$, and then $10 \mu \mathrm{L}(0.05 \mathrm{mmol})$ of decylamine was added. The reaction mixture was stirred for an additional $30 \mathrm{~min}$. Separately, $3.5 \mathrm{mg}(0.0315 \mathrm{mmol})$ of $\mathrm{CH}_{3} \mathrm{NH}_{3} \mathrm{Br}$ and $18.7 \mathrm{mg}(0.05 \mathrm{mmol})$ of $\mathrm{PbBr}_{2}$ were dissolved in 100 and $200 \mu \mathrm{L}$ of DMF, respectively. The $\mathrm{CH}_{3} \mathrm{NH}_{3} \mathrm{Br}$ solution and $\mathrm{PbBr}_{2}$ solution were injected simultaneously. The solution color turned light yellow almost instantaneously, and at $30 \mathrm{~s}, 200 \mu \mathrm{L}$ of the reaction mixture was injected into $2 \mathrm{~mL}$ of acetone to quench the reaction. The purification steps were identical to those described for $\mathrm{CH}_{3} \mathrm{NH}_{3} \mathrm{PbBr}_{3}$ quantum platelet synthesis.

UV-vis Absorbance, Photoluminescence, Photoluminescence Lifetime, and Absolute Quantum Yield Measurements. The absorption spectra were collected using a Varian-Cary 50 Scan $\mathrm{UV}$-vis spectrophotometer with $1 \mathrm{~cm}$ quartz cuvettes over a range of $300-800 \mathrm{~nm}$. All spectra were recorded in toluene, and toluene was used as a background for all measurements. The photoluminescence emission (PL) spectra were collected using a Cary Eclipse fluorescence spectrophotometer from Varian Instruments with $1 \mathrm{~cm}$ quartz cuvettes. For measurement of the excitation energy dependence of the PL intensity, we used the same identical solution of quantum platelets and cubes and same cuvette to collect the PL spectra at different excitation wavelengths. The absorbance value between 300 and $390 \mathrm{~nm}$ was $0.47-0.15$. The lifetime measurements were recorded using a time-correlated single photon counting (TCSPC) experimental setup. The data acquisition card was from Edinburgh Instrument (TCC900). The laser was a $405 \mathrm{~nm}$ pulsed laser from PICQUANT (LDH-D-C-405M. CW-80 MHz) with pulse width of $<100$ ps. The detector was a photomultiplier tube from HAMAMATSU (HT42240). The following Kohlrauch-Williams-Watts (KWW) stretchedexponential equations (eqs 1 and 2), which are very commonly used to determine the average lifetime $(\tau)$ of semiconductor nanocrystals, ${ }^{54-56}$ were used to determine the excited state lifetime of our perovskite nanocrystals. Here, $I(t)$ and $I_{0}$ are the PL intensities at time $t$ and zero. $\tau_{\mathrm{KWW}}$ and $\beta$ are the KWW decay time and the stretch factor, respectively.

$$
\begin{aligned}
& I(t)=I_{0} \exp \left(-\left[\frac{t}{\tau_{\mathrm{KWW}}}\right]^{\beta}\right) \\
& \tau=\frac{1}{\beta} \Gamma\left(\frac{1}{\beta}\right) \tau_{\mathrm{KWW}}
\end{aligned}
$$

where $\Gamma(x)$ is the gamma function. Absolute quantum yield was measured using the Hamamatsu absolute PL spectrophotometer C11347 with a $150 \mathrm{~W}$ xenon light source and an integrating sphere (from Spectralon).

Elemental Analysis. A field emission scanning electron microscopy system (Hitachi S-4700), which was equipped with an energy dispersive X-ray (EDS) analyzer, was used to determine the $\mathrm{Pb} / \mathrm{Br}$ ratio.

Transmission Electron Microscopy (TEM) Characterization. The samples for TEM analysis were prepared inside a glovebox by placing $10 \mu \mathrm{L}$ of the sample dissolved in toluene onto a formvercoated copper grid (Electron Microscopy Science). The sample was allowed to set for $30 \mathrm{~s}$, and any excess solution was removed by wicking with a Kimwipe in order to avoid particle aggregation. Images were acquired using a JEOL-3200FS-JEM instrument operating at 200 $\mathrm{kV}$. At least 300 quantum platelets were analyzed to obtain the averages for width, length, and thickness, and 300 quantum cubes were counted for edge-to-edge distance measurement.

Powder X-ray Diffraction (PXRD) and Small Angle X-ray Scattering (SAXS) Analyses. Wide-angle PXRD was recorded on a Rigaku MiniFlexTM II $(\mathrm{Cu} \mathrm{K} \alpha)$ instrument. Samples were prepared by dropcasting the purified quantum platelets or cubes on piranha cleaned glass coverslips. (Caution: piranha solution is highly reactive and must be handled with extreme caution. It reacts violently with organic materials and may not be stored in tightly closed vessels.) SAXS measurements for quantum platelets were conducted on the beamline 12-1D-C at Argone's advanced photon source. The samples on glass coverslips were mounted vertically such that the glass was perpendicular to the beam. They were then rotated using a motor at a frequency ranging from 3 to $5 \mathrm{~Hz}$. Two-dimensional scattering data was taken, which was averaged and integrated of the $\chi$ angle to obtain intensity versus $q\left(\AA^{-1}\right)$.

\section{ASSOCIATED CONTENT}

\section{S Supporting Information}

The Supporting Information is available free of charge on the ACS Publications website at DOI: 10.1021/acs.chemmater.6b05393.

Additional TEM images; histograms for size/shape analysis; EDS, UV-vis, photoluminescence, FTIR, and NMR spectra; PL intensity plots; tables; references (PDF) 


\section{AUTHOR INFORMATION}

\section{Corresponding Author}

*E-mail: rsardar@iupui.edu.

ORCID $\odot$

Rajesh Sardar: 0000-0001-9680-1301

\section{Author Contributions}

The manuscript was written through contributions of all authors.

\section{Notes}

The authors declare no competing financial interest.

\section{ACKNOWLEDGMENTS}

The experimental work is supported by National Science Foundation (Grant No. 1604617). XRD and EDX analyses were conducted with Hitachi and Bruker instruments purchased using NSF-MRI awards (No. MRI-1229514 and No. MRI-1429241, respectively). This research used resources of the Advanced Photon Source, a U.S. Department of Energy (DOE) Office of Science User Facility operated for the DOE Office of Science by Argonne National Laboratory under Contract No. DE-AC02-06CH11357. We also thank Dr. P. Dutta for helpful discussion on lifetime measurements.

\section{REFERENCES}

(1) Kojima, A.; Teshima, K.; Shirai, Y.; Miyasaka, T. Organometal Halide Perovskites as Visible-Light Sensitizers for Photovoltaic Cells. J. Am. Chem. Soc. 2009, 131, 6050-6051.

(2) Hao, F.; Stoumpos, C. C.; Cao, D. H.; Chang, R. P. H.; Kanatzidis, M. G. Lead-free solid-state organic-inorganic halide perovskite solar cells. Nat. Photonics 2014, 8, 489-494.

(3) Heo, J. H.; Im, S. H.; Noh, J. H.; Mandal, T. N.; Lim, C.-S.; Chang, J. A.; Lee, Y. H.; Kim, H.-j.; Sarkar, A.; Nazeeruddin, M. K.; et al. Efficient inorganic-organic hybrid heterojunction solar cells containing perovskite compound and polymeric hole conductors. Nat. Photonics 2013, 7, 486-491.

(4) Burschka, J.; Pellet, N.; Moon, S.-J.; Humphry-Baker, R.; Gao, P.; Nazeeruddin, M. K.; Graetzel, M. Sequential deposition as a route to high-performance perovskite-sensitized solar cells. Nature 2013, 499, 316-319.

(5) Jeon, N. J.; Noh, J. H.; Yang, W. S.; Kim, Y. C.; Ryu, S.; Seo, J.; Seok, S. I. Compositional engineering of perovskite materials for highperformance solar cells. Nature 2015, 517, 476-480.

(6) Liu, M.; Johnston, M. B.; Snaith, H. J. Efficient planar heterojunction perovskite solar cells by vapour deposition. Nature 2013, 501, 395-398.

(7) deQuilettes, D. W.; Vorpahl, S. M.; Stranks, S. D.; Nagaoka, H.; Eperon, G. E.; Ziffer, M. E.; Snaith, H. J.; Ginger, D. S. Impact of microstructure on local carrier lifetime in perovskite solar cells. Science 2015, 348, 683-686.

(8) Lee, M. M.; Teuscher, J.; Miyasaka, T.; Murakami, T. N.; Snaith, H. J. Efficient Hybrid Solar Cells Based on Meso-Superstructured Organometal Halide Perovskites. Science 2012, 338, 643-647.

(9) Nie, W.; Tsai, H.; Asadpour, R.; Blancon, J.-C.; Neukirch, A. J.; Gupta, G.; Crochet, J. J.; Chhowalla, M.; Tretiak, S.; Alam, M. A.; et al. High-efficiency solution-processed perovskite solar cells with millimeter-scale grains. Science 2015, 347, 522-525.

(10) Shi, D.; Adinolfi, V.; Comin, R.; Yuan, M.; Alarousu, E.; Buin, A.; Chen, Y.; Hoogland, S.; Rothenberger, A.; Katsiev, K.; et al. Low trap-state density and long carrier diffusion in organolead trihalide perovskite single crystals. Science 2015, 347, 519-522.

(11) Stranks, S. D.; Eperon, G. E.; Grancini, G.; Menelaou, C.; Alcocer, M. J. P.; Leijtens, T.; Herz, L. M.; Petrozza, A.; Snaith, H. J. Electron-Hole Diffusion Lengths Exceeding 1 Micrometer in an Organometal Trihalide Perovskite Absorber. Science 2013, 342, 341344.
(12) Xing, G.; Mathews, N.; Sun, S.; Lim, S. S.; Lam, Y. M.; Graetzel, M.; Mhaisalkar, S.; Sum, T. C. Long-Range Balanced Electron- and Hole-Transport Lengths in Organic-Inorganic CH3NH3PbI3. Science 2013, 342, 344-347.

(13) Zhou, H.; Chen, Q.; Li, G.; Luo, S.; Song, T.-b.; Duan, H.-S.; Hong, Z.; You, J.; Liu, Y.; Yang, Y. Interface engineering of highly efficient perovskite solar cells. Science 2014, 345, 542-546.

(14) Tan, Z.-K.; Moghaddam, R. S.; Lai, M. L.; Docampo, P.; Higler, R.; Deschler, F.; Price, M.; Sadhanala, A.; Pazos, L. M.; Credgington, D.; et al. Bright light-emitting diodes based on organometal halide perovskite. Nat. Nanotechnol. 2014, 9, 687-692.

(15) Xing, G.; Mathews, N.; Lim, S. S.; Yantara, N.; Liu, X.; Sabba, D.; Grätzel, M.; Mhaisalkar, S.; Sum, T. C. Low-temperature solutionprocessed wavelength-tunable perovskites for lasing. Nat. Mater. 2014, $13,476-480$.

(16) Zhu, H.; Fu, Y.; Meng, F.; Wu, X.; Gong, Z.; Ding, Q.; Gustafsson, M. V.; Trinh, M. T.; Jin, S.; Zhu, X. Y. Lead halide perovskite nanowire lasers with low lasing thresholds and high quality factors. Nat. Mater. 2015, 14, 636-642.

(17) NREL. http://www.nrel.gov/ncpv/images/efficiency_chart.jpg (accessed April 11, 2017)

(18) Kamat, P. V.; Tvrdy, K.; Baker, D. R.; Radich, J. G. Beyond Photovoltaics: Semiconductor Nanoarchitectures for Liquid-Junction Solar Cells. Chem. Rev. 2010, 110, 6664-6688.

(19) Talapin, D. V.; Lee, J.-S.; Kovalenko, M. V.; Shevchenko, E. V. Prospects of Colloidal Nanocrystals for Electronic and Optoelectronic Applications. Chem. Rev. 2010, 110, 389-458.

(20) Tang, J.; Kemp, K. W.; Hoogland, S.; Jeong, K. S.; Liu, H.; Levina, L.; Furukawa, M.; Wang, X.; Debnath, R.; Cha, D.; et al. Colloidal-quantum-dot photovoltaics using atomic-ligand passivation. Nat. Mater. 2011, 10, 765-771.

(21) Gur, I.; Fromer, N. A.; Geier, M. L.; Alivisatos, A. P. Air-Stable All-Inorganic Nanocrystal Solar Cells Processed from Solution. Science 2005, 310, 462-465.

(22) Huynh, W. U.; Dittmer, J. J.; Alivisatos, A. P. Hybrid NanorodPolymer Solar Cells. Science 2002, 295, 2425-2427.

(23) Talapin, D. V.; Murray, C. B. PbSe Nanocrystal Solids for n- and p-Channel Thin Film Field-Effect Transistors. Science 2005, 310, 8689.

(24) Schmidt, L. C.; Pertegás, A.; González-Carrero, S.; Malinkiewicz, O.; Agouram, S.; Mínguez Espallargas, G.; Bolink, H. J.; Galian, R. E.; Pérez-Prieto, J. Nontemplate Synthesis of CH3NH3PbBr3 Perovskite Nanoparticles. J. Am. Chem. Soc. 2014, 136, 850-853.

(25) Zhang, F.; Zhong, H.; Chen, C.; Wu, X.-g.; Hu, X.; Huang, H.; Han, J.; Zou, B.; Dong, Y. Brightly Luminescent and Color-Tunable Colloidal $\mathrm{CH} 3 \mathrm{NH} 3 \mathrm{PbX} 3(\mathrm{X}=\mathrm{Br}, \mathrm{I}, \mathrm{Cl})$ Quantum Dots: Potential Alternatives for Display Technology. ACS Nano 2015, 9, 4533-4542.

(26) Zhu, F.; Men, L.; Guo, Y.; Zhu, Q.; Bhattacharjee, U.; Goodwin, P. M.; Petrich, J. W.; Smith, E. A.; Vela, J. Shape Evolution and Single Particle Luminescence of Organometal Halide Perovskite Nanocrystals. ACS Nano 2015, 9, 2948-2959.

(27) Fu, Y.; Meng, F.; Rowley, M. B.; Thompson, B. J.; Shearer, M. J.; Ma, D.; Hamers, R. J.; Wright, J. C.; Jin, S. Solution Growth of Single Crystal Methylammonium Lead Halide Perovskite Nanostructures for Optoelectronic and Photovoltaic Applications. J. Am. Chem. Soc. 2015, 137, 5810-5818.

(28) Aharon, S.; Etgar, L. Two Dimensional Organometal Halide Perovskite Nanorods with Tunable Optical Properties. Nano Lett. 2016, 16, 3230-3235.

(29) Vybornyi, O.; Yakunin, S.; Kovalenko, M. V. Polar-solvent-free colloidal synthesis of highly luminescent alkylammonium lead halide perovskite nanocrystals. Nanoscale 2016, 8, 6278-6283.

(30) Protesescu, L.; Yakunin, S.; Bodnarchuk, M. I.; Krieg, F.; Caputo, R.; Hendon, C. H.; Yang, R. X.; Walsh, A.; Kovalenko, M. V. Nanocrystals of Cesium Lead Halide Perovskites (CsPbX3, X $=\mathrm{Cl}, \mathrm{Br}$, and I): Novel Optoelectronic Materials Showing Bright Emission with Wide Color Gamut. Nano Lett. 2015, 15, 3692-3696.

(31) Sun, S.; Yuan, D.; Xu, Y.; Wang, A.; Deng, Z. Ligand-Mediated Synthesis of Shape-Controlled Cesium Lead Halide Perovskite 
Nanocrystals via Reprecipitation Process at Room Temperature. ACS Nano 2016, 10, 3648-3657.

(32) Bekenstein, Y.; Koscher, B. A.; Eaton, S. W.; Yang, P.; Alivisatos, A. P. Highly Luminescent Colloidal Nanoplates of Perovskite Cesium Lead Halide and Their Oriented Assemblies. J. Am. Chem. Soc. 2015, 137, 16008-16011.

(33) Jellicoe, T. C.; Richter, J. M.; Glass, H. F. J.; Tabachnyk, M.; Brady, R.; Dutton, S. E.; Rao, A.; Friend, R. H.; Credgington, D.; Greenham, N. C.; et al. Synthesis and Optical Properties of Lead-Free Cesium Tin Halide Perovskite Nanocrystals. J. Am. Chem. Soc. 2016, 138, 2941-2944.

(34) Shamsi, J.; Dang, Z.; Bianchini, P.; Canale, C.; Stasio, F. D.; Brescia, R.; Prato, M.; Manna, L. Colloidal Synthesis of Quantum Confined Single Crystal CsPbBr3 Nanosheets with Lateral Size Control up to the Micrometer Range. J. Am. Chem. Soc. 2016, 138, $7240-7243$.

(35) Zhang, D.; Eaton, S. W.; Yu, Y.; Dou, L.; Yang, P. SolutionPhase Synthesis of Cesium Lead Halide Perovskite Nanowires. J. Am. Chem. Soc. 2015, 137, 9230-9233.

(36) Akkerman, Q. A.; Motti, S. G.; Srimath Kandada, A. R.; Mosconi, E.; D’Innocenzo, V.; Bertoni, G.; Marras, S.; Kamino, B. A.; Miranda, L.; De Angelis, F.; et al. Solution Synthesis Approach to Colloidal Cesium Lead Halide Perovskite Nanoplatelets with Monolayer-Level Thickness Control. J. Am. Chem. Soc. 2016, 138, $1010-1016$.

(37) Lhuillier, E.; Pedetti, S.; Ithurria, S.; Nadal, B.; Heuclin, H.; Dubertret, B. Two-Dimensional Colloidal Metal Chalcogenides Semiconductors: Synthesis, Spectroscopy, and Applications. Acc. Chem. Res. 2015, 48, 22-30.

(38) Rossi, D.; Han, J. H.; Jung, W.; Cheon, J.; Son, D. H. Orientational Control of Colloidal 2D-Layered Transition Metal Dichalcogenide Nanodiscs via Unusual Electrokinetic Response. ACS Nano 2015, 9, 8037-8043.

(39) Son, J. S.; Wen, X.-D.; Joo, J.; Chae, J.; Baek, S.-i.; Park, K.; Kim, J. H.; An, K.; Yu, J. H.; Kwon, S. G.; et al. Large-Scale Soft Colloidal Template Synthesis of $1.4 \mathrm{~nm}$ Thick CdSe Nanosheets. Angew. Chem., Int. Ed. 2009, 48, 6861-6864.

(40) Wang, Y.; Zhang, Y.; Wang, F.; Giblin, D. E.; Hoy, J.; Rohrs, H. W.; Loomis, R. A.; Buhro, W. E. The Magic-Size Nanocluster (CdSe)34 as a Low-Temperature Nucleant for Cadmium Selenide Nanocrystals; Room-Temperature Growth of Crystalline Quantum Platelets. Chem. Mater. 2014, 26, 2233-2243.

(41) Ithurria, S.; Bousquet, G.; Dubertret, B. Continuous Transition from 3D to 1D Confinement Observed during the Formation of CdSe Nanoplatelets. J. Am. Chem. Soc. 2011, 133, 3070-3077.

(42) Jung, W.; Lee, S.; Yoo, D.; Jeong, S.; Miró, P.; Kuc, A.; Heine, T.; Cheon, J. Colloidal Synthesis of Single-Layer MSe2 (M = Mo, W) Nanosheets via Anisotropic Solution-Phase Growth Approach. J. Am. Chem. Soc. 2015, 137, 7266-7269.

(43) Yoo, D.; Kim, M.; Jeong, S.; Han, J.; Cheon, J. Chemical Synthetic Strategy for Single-Layer Transition-Metal Chalcogenides. J. Am. Chem. Soc. 2014, 136, 14670-14673.

(44) Liu, Y.-H.; Wang, F.; Wang, Y.; Gibbons, P. C.; Buhro, W. E. Lamellar Assembly of Cadmium Selenide Nanoclusters into Quantum Belts. J. Am. Chem. Soc. 2011, 133, 17005-17013.

(45) Ithurria, S.; Tessier, M. D.; Mahler, B.; Lobo, R. P. S. M.; Dubertret, B.; Efros, A. L. Colloidal nanoplatelets with twodimensional electronic structure. Nat. Mater. 2011, 10, 936-941.

(46) Grim, J. Q.; Christodoulou, S.; Di Stasio, F.; Krahne, R.; Cingolani, R.; Manna, L.; Moreels, I. Continuous-wave biexciton lasing at room temperature using solution-processed quantum wells. Nat. Nanotechnol. 2014, 9, 891-895.

(47) Tyagi, P.; Arveson, S. M.; Tisdale, W. A. Colloidal Organohalide Perovskite Nanoplatelets Exhibiting Quantum Confinement. J. Phys. Chem. Lett. 2015, 6, 1911-1916.

(48) Sichert, J. A.; Tong, Y.; Mutz, N.; Vollmer, M.; Fischer, S.; Milowska, K. Z.; García Cortadella, R.; Nickel, B.; Cardenas-Daw, C.; Stolarczyk, J. K.; et al. Quantum Size Effect in Organometal Halide Perovskite Nanoplatelets. Nano Lett. 2015, 15, 6521-6527.
(49) Ha, S. T.; Liu, X.; Zhang, Q.; Giovanni, D.; Sum, T. C.; Xiong, Q. Synthesis of Organic-Inorganic Lead Halide Perovskite Nanoplatelets: Towards High-Performance Perovskite Solar Cells and Optoelectronic Devices. Adv. Opt. Mater. 2014, 2, 838-844.

(50) Schliehe, C.; Juarez, B. H.; Pelletier, M.; Jander, S.; Greshnykh, D.; Nagel, M.; Meyer, A.; Foerster, S.; Kornowski, A.; Klinke, C.; Weller, H. Ultrathin $\mathrm{PbS}$ Sheets by Two-Dimensional Oriented Attachment. Science 2010, 329, 550-553.

(51) Dou, L.; Wong, A. B.; Yu, Y.; Lai, M.; Kornienko, N.; Eaton, S. W.; Fu, A.; Bischak, C. G.; Ma, J.; Ding, T.; et al. Atomically thin twodimensional organic-inorganic hybrid perovskites. Science 2015, 349, $1518-1521$

(52) Son, J. S.; Wen, X.-D.; Joo, J.; Chae, J.; Baek, S.-i.; Park, K.; Kim, J. H.; An, K.; Yu, J. H.; Kwon, S. G.; et al. Large-Scale Soft Colloidal Template Synthesis of $1.4 \mathrm{~nm}$ Thick CdSe Nanosheets. Angew. Chem., Int. Ed. 2009, 48, 6861-6864.

(53) Tong, Y.; Ehrat, F.; Vanderlinden, W.; Cardenas-Daw, C.; Stolarczyk, J. K.; Polavarapu, L.; Urban, A. S. Dilution-Induced Formation of Hybrid Perovskite Nanoplatelets. ACS Nano 2016, 10, 10936-10944.

(54) Dutta, P.; Beaulac, R. Photoluminescence Quenching of Colloidal CdSe and CdTe Quantum Dots by Nitroxide Free Radicals. Chem. Mater. 2016, 28, 1076-1084.

(55) Fisher, B. R.; Eisler, H.-J.; Stott, N. E.; Bawendi, M. G. Emission Intensity Dependence and Single-Exponential Behavior In Single Colloidal Quantum Dot Fluorescence Lifetimes. J. Phys. Chem. B 2004, 108, 143-148.

(56) van Driel, A. F.; Nikolaev, I. S.; Vergeer, P.; Lodahl, P.; Vanmaekelbergh, D.; Vos, W. L. Statistical analysis of time-resolved emission from ensembles of semiconductor quantum dots: Interpretation of exponential decay models. Phys. Rev. B: Condens. Matter Mater. Phys. 2007, 75, 035329.

(57) Hoy, J.; Morrison, P. J.; Steinberg, L. K.; Buhro, W. E.; Loomis, R. A. Excitation Energy Dependence of the Photoluminescence Quantum Yields of Core and Core/Shell Quantum Dots. J. Phys. Chem. Lett. 2013, 4, 2053-2060.

(58) Micic, O. I.; Ahrenkiel, S. P.; Nozik, A. J. Synthesis of extremely small InP quantum dots and electronic coupling in their disordered solid films. Appl. Phys. Lett. 2001, 78, 4022-4024.

(59) Bayer, M.; Hawrylak, P.; Hinzer, K.; Fafard, S.; Korkusinski, M.; Wasilewski, Z. R.; Stern, O.; Forchel, A. Coupling and Entangling of Quantum States in Quantum Dot Molecules. Science 2001, 291, 451453.

(60) Sugimoto, T. Preparation of monodispersed colloidal particles. Adv. Colloid Interface Sci. 1987, 28, 65-108.

(61) LaMer, V. K.; Dinegar, R. H. Theory, Production and Mechanism of Formation of Monodispersed Hydrosols. J. Am. Chem. Soc. 1950, 72, 4847-4854.

(62) Pacholski, C.; Kornowski, A.; Weller, H. Self-Assembly of $\mathrm{ZnO}$ From Nanodots to Nanorods. Angew. Chem., Int. Ed. 2002, 41, 11881191.

(63) Shevchenko, E. V.; Talapin, D. V.; Kotov, N. A.; O’Brien, S.; Murray, C. B. Structural diversity in binary nanoparticle superlattices. Nature 2006, 439, 55-59.

(64) Li, D.; Nielsen, M. H.; Lee, J. R. I.; Frandsen, C.; Banfield, J. F.; De Yoreo, J. J. Direction-Specific Interactions Control Crystal Growth by Oriented Attachment. Science 2012, 336, 1014-1018.

(65) Yu, T.; Lim, B.; Xia, Y. Aqueous-Phase Synthesis of SingleCrystal Ceria Nanosheets. Angew. Chem., Int. Ed. 2010, 49, 44844487.

(66) Cölfen, H.; Mann, S. Higher-Order Organization by Mesoscale Self-Assembly and Transformation of Hybrid Nanostructures. Angew. Chem., Int. Ed. 2003, 42, 2350-2365.

(67) Ghezelbash, A.; Korgel, B. A. Nickel Sulfide and Copper Sulfide Nanocrystal Synthesis and Polymorphism. Langmuir 2005, 21, 94519456.

(68) Tang, Z.; Zhang, Z.; Wang, Y.; Glotzer, S. C.; Kotov, N. A. SelfAssembly of CdTe Nanocrystals into Free-Floating Sheets. Science 2006, 314, 274-278. 
(69) Akkerman, Q. A.; D’Innocenzo, V.; Accornero, S.; Scarpellini, A.; Petrozza, A.; Prato, M.; Manna, L. Tuning the Optical Properties of Cesium Lead Halide Perovskite Nanocrystals by Anion Exchange Reactions. J. Am. Chem. Soc. 2015, 137, 10276-10281.

(70) Lee, S.-M.; Jun, Y.-w.; Cho, S.-N.; Cheon, J. Single-Crystalline Star-Shaped Nanocrystals and Their Evolution: Programming the Geometry of Nano-Building Blocks. J. Am. Chem. Soc. 2002, 124, $11244-11245$.

(71) Xia, Y.; Xia, X.; Peng, H.-C. Shape-Controlled Synthesis of Colloidal Metal Nanocrystals: Thermodynamic versus Kinetic Products. J. Am. Chem. Soc. 2015, 137, 7947-7966.

(72) Tao, A. R.; Habas, S.; Yang, P. Shape Control of Colloidal Metal Nanocrystals. Small 2008, 4, 310-325.

(73) Jun, Y.-w.; Choi, J.-s.; Cheon, J. Shape Control of Semiconductor and Metal Oxide Nanocrystals through Nonhydrolytic Colloidal Routes. Angew. Chem., Int. Ed. 2006, 45, 3414-3439.

(74) Peng, X. Mechanisms for the Shape-Control and ShapeEvolution of Colloidal Semiconductor Nanocrystals. Adv. Mater. 2003, $15,459-463$.

(75) Teunis, M. B.; Jana, A.; Dutta, P.; Johnson, M. A.; Mandal, M.; Muhoberac, B. B.; Sardar, R. Mesoscale Growth and Assembly of Bright Luminescent Organolead Halide Perovskite Quantum Wires. Chem. Mater. 2016, 28, 5043-5054.

(76) Teunis, M. B.; Lawrence, K. N.; Dutta, P.; Siegel, A. P.; Sardar, R. Pure white-light emitting ultrasmall organic-inorganic hybrid perovskite nanoclusters. Nanoscale 2016, 8, 17433-17439. 